$$
\text { CONF-8409167-3 }
$$

\title{
ANALYSIS OF UNCERTAINTIES IN CRAC2 CALCULATIONS: WET DEPOSITION AND PLUME RISE*
}

CONF $-8409169--3$

\author{
R. C. Ward ${ }^{t}$ and D. C. Kocher ${ }^{t}$ \\ Oak Ridge National Laboratory \\ Oak Ridge, TN 37831
}

DE85 005361

B. B. Hicks, R. P. Hosker, Jr., J.-Y. Ku, "“ and K. S. Rao

Atmospheric Turbulence and Diffusion Laboratory

National Oceanic and Atmospheric Administration

Oak Ridge, TN 37831

\section{ABSTRACT}

We have studied the sensitivity of results from the CRAC2 computer code, which predicts health impacts from a reactor-accident scenario, to uncertainties in selected meteorological models and parameters. The sources of uncertainty examined include the models for plume rise and wet deposition and the meteorological bin-sampling procedure. An alternative plume-rise model usually had little effect on predicted health impacts. In an alternative wet-deposition model, the scavenging rate depends oniy on storm type, rather than on rainfall rate and atmospheric stability class as in the CRAC2 model. Use of the alternative wet-deposition model in meteorological bin-sampling runs decreased predicted mean early injuries by as much as a factor of $2-3$ and, for large release heights and sensible heat rates, decreased mean early fatalities by nearly ar order of magnitude. The bin-sampling procedure in CRAC2 was expanded by dividing each rain bin into four bins that depend on rainfall rate. Use of the modified bin structure in conjunction with the CRAC2 wet-deposition model changed all predicted health impacts by less than a factor of 2 .

'Research sponsored by the Division of Systems Integration, Office of Nuclear Reactor Regulation, U.S. Nuclear Regulatory Commission under Interagency Agreement DOE 40-550-75 with the U.S. Department of Energy under contract DE-AC05-940R21400 with Martin Marietta Einergy Systems, Inc.

'Computing and Telecommunications Division

tHealth and Safety Research Division

"Permanent address: Department of Atwospheric Sciences, State University of New York at Albany, Albany, NY 12222

By acceptence of this erticle, the publisher or recipient acknowledoes the U.S. Government's right to retain a nonexclusive, royalty-free licanse in and to any copyright covering the article.

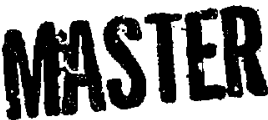

OISTRIBUTON OF THIS DOCUMENT IS UHLMAITED 
KEY WORDS: CRAC2, Wet Deposition, Plume Rise, Uncertainty, Scnsitivity,

Bin-Sampling, Meteorological Models, Health Effects.

\section{INTRODUCTION}

The CRAC2 computer code ${ }^{1,2}$ estimates the health impacıs and economic costs that could result from a hypothetical nuclear reactor accident. CRAC2 is a revised version of the CRAC code that was used in the Reactor Safety Study. ${ }^{3}$ The code utilizes hourly meteorological data (i.e., wind speed and direction, atmospheric stability class, and precipitation rate) in a straight-line, Gaussian-plume model to describe radionuclide transport in the atmosphere, and includes models for plume depletion via wet and dry depostiion. Results can be obtained either for single weather sequences, which we refer to as single trials, or for importance sampling ${ }^{1}$ from one year's weather data, which we refer to as meteorological bin-sampling. Bin-sampling runs produce statistical distributions of output, from which mean values averaged over the results for each sampled weather sequence can be obtained.

This paper presents a study of the sensitivity of health impacts predicted by the CRAC2 code to uncertainties in selected meteorological models and parameters. The sources of uncertainty studied include the use of alternative models for plume rise and wet deposition and an alternative procedure for meteorological bin-sampling. These models can affect predicted early fatalities, early injuries, and latent cancer fatalities. ${ }^{\prime}$

The sensitivity studies were performed with a prescribed release of radionuclides, a non-uniform population distribution, a single evacuation model, and one year's meteorological data from a reactor site. Three release heights $(\mathrm{RH}=0,25$, and $50 \mathrm{~m})$ and two sensible heat rates $\left(\mathrm{F}=10^{4}\right.$ and $10^{6}$ $\mathrm{cal} / \mathrm{s}$ ) were used in the calculations.

\section{ANALYSIS OF PLUME-RISE MODELS}

The plume-rise model contained in $\mathrm{CRAC}^{4}$ and the alternative model investigated in this study ${ }^{5}$ were both developed by Briggs. The two models are identical for stable atmospheric conditions. For unstable and neutral conditions, the maximum plume rise, $\triangle H$, in the $C R A C 2$ model is given by: 


$$
\Delta H=6.11(F P)^{3 / 5}(R H)^{2 / 5} / U
$$

where RH is the release height $(\mathrm{m}), \mathrm{U}$ is the wind speed $(\mathrm{m} / \mathrm{s})$ at the release and FP is the sensible heat rate $\left(\mathrm{m}^{4} / \mathrm{sec}^{3}\right)\left[\mathrm{FP}=3.7 \times 10^{-5} \mathrm{~F}\right.$ where $\mathrm{F}$ is in cal/sec]. To avoid zero plume rise when $\mathrm{RH}$ is zero, the program resets $\mathrm{RH}$ to 1 meter. The maximum plume rise in the alternative model ${ }^{5}$ is given by the minimum of $\Delta \mathrm{H}_{1}$ or $\Delta \mathrm{H}_{2}$ :

$$
\begin{aligned}
& \Delta H_{1}=30(F P / U)^{3 / 5} \\
& \Delta H_{2}=24\left(F P / U^{3}\right)^{3 / 5}\left(R H+200 F P / U^{3}\right)^{2 / 5} .
\end{aligned}
$$

where the first formula will generally apply in convective or unstable conditions and the second in neutral conditions. The plume heights are obtained by adding the release heights to the plume rise.

For unstable and neutral conditions, the alternative model generally gives greater plume heights than the model in CRAC2, with the largest increases occurring for zero release height. However, in both single-trial and bin-sampling runs, predicted health impacts usually showed little sensitivity to the plume-rise model; i.e., the results changed by $40 \%$ or less. Exceptions occurred for $\mathrm{RH}=0$ and $\mathrm{F}=$ $10^{6} \mathrm{cal} / \mathrm{s}$, where the alternative model decreased early fatalities from 48 to 0 in a single-trial run with $\mathrm{n}$ rain (the plume height increased from 16 to $120 \mathrm{~m}$ in this case) and by a factor of 3 in a binsampling run.

\section{ANALYSIS OF WET-DEPOSITION MODIELS}

The wet-deposition model in CRAC2 uses a scavenging rate, $\Lambda$, of the form $\Delta=C R$, where $R$ is the precipitation rate in $\mathrm{mm} / \mathrm{hr}$ and the washout coefficient, $\mathrm{C}$, is $10^{-3}(\mathrm{~mm}-\mathrm{s} / \mathrm{hr})^{-1}$ for unstable and neutral conditions and $10^{-4}(\mathrm{~mm}-\mathrm{s} / \mathrm{hr})^{-1}$ for stable conditions. ${ }^{1}$ This model does not properly account for certain cases such as a strong convective storm at night, where unstable conditions might prevail at ground level, or a stratiform system in daytime, e.g., a winter raisstorm. Thus, we felt that a model with constant scavenging rates that depend only on storm type rather than ground-level stability and rainfall rate would be a reasonable alternative. On the basis of measurements of precipitation scavenging for sub-cloud "washout" conditions, ${ }^{6,7}$ which are expected in most continuous or frontal rain 
storms, and for in-cloud "rainout" conditions, ${ }^{6,8,9}$ which are likely with convective storms, we chose scavenging rates of $\Lambda=5 \times 10^{-5} \mathrm{~s}^{-1}$ for continuous rain and $\Lambda=10^{-3} \mathrm{~s}^{-1}$ for convective rain. The scavenging rate in the aiternative model is usually less than in the CRAC2 model, particularly for continuous rain during unstable or neutral conditions. In our analysis, the assignment $c$ : storm type to precipitation events was based on actual meteorological observations.

We studied the sensitivity of CRAC2 results to the wet-deposition model in single-trial runs with rain and in bin-sampling runs. The weather sequences for the single-trial runs were chosen to give different combinations of storm types, atmospheric stability classes, wind speeds, and rainfall rates, durations, and locations. In the single-trial runs, the predicted health impacts often were very sensitive to the wet-deposition model, and the effects of the alternative model on the results often were quite different for the different weather sequences. These results are discussed below.

Three weather sequences involving continuous rain were investigated in single-trial runs. The first was studied only for $\mathrm{RH}=50 \mathrm{~m}$ and $\mathrm{F}=10^{6} \mathrm{cal} / \mathrm{s}$. This sequence involved unstable and neutral conditions and continuous rain which began at the distance from the release point to which the evacuated population was assumed to be relocated. Use of the alternative model decreased predicted early fatalities from 3200 to nearly 0 , increased early injuries from 0 to more than 10,000 , and increased latent cancer fatalities by a factor of 40 . In this and other cases where large changes in early fatalities or injuries were obtained, the changes are also due in part to the presence of thresholds in the dose-response models.' For the second weather sequence, which involved unstable and neutral conditions and continuous rain throughout the sequence, early fatalities were nearly zero for all values of RH and F, but early injuries and latent cancer fatalities increased with the alternative model by a factor of 10-20. The third weather sequence involved mostly stable conditions and continuous rain throughout, with heavy rain beginning at a distance of about $30 \mathrm{~km}$ from the release point. In this case, early fatalities changed by less than $15 \%$ with the alternative model, early injuries by $10-50 \%$, and latent cancer fatalities by $25-50 \%$.

Two weather sequences involving convective storms and unstable or neutral conditions were studied in single-trial runs. The sequences differed mainly in the distance from the release point at which the storm began. For a sequence where the storm began at about $30 \mathrm{~km}$, use of the alternative model increased predicted early fatalities by more than an order of magnitude for all values of $\mathrm{RH}$ and $F$. Early injuries and latent cancer fatalities also increased, but only by about 40\%. For a weather sequence where the storm began at about $5 \mathrm{~km}$, the changes in all predicted health impacts were insignificant. 
In tin-sampling runs, use of the alternative wet-deposition model increased predicted mean early fatalities for most values of $\mathrm{RH}$ and $\mathrm{F}$, but only by $40 \%$ or less. However, for $\mathrm{RH}=25$ or $50 \mathrm{~m}$ and $\mathrm{F}=10^{6} \mathrm{cal} / \mathrm{s}$, mean early fatalities decreased by a factor of 5-7 when the same set of weather sequences was sampled in comparing the two wet-deposition models, but increased by a factor of 2 when a different set of weather sequences was sampled with the alternative model. The important feature of these runs was that mean early fatalities using either wet-deposition model were small, i.e., less than 20 , and most of the weather sequences sampled gave a null result. Thus, we are observing the serısitivity of mean early fatalities in bin-sampling runs to whether or not the sampling scheme selects those rare single trials which given unusually large early fatalities. For all values of RH and F, mean early irijuries decreased between $10 \%$ and a factor of 3 with the alternative model, and mean latent cancer fatalities increased by less than $30 \%$.

\section{ANALYSIS OF MODIFICATIONS IN METEOROLOGICAL BIN-SAMPLING}

In the meteorological bin-sampling procedure in CRAC2, each of the 8760 hours of weather data in one year is sorted into une of 29 bins, 7 of which represent weather sequences with rain occurring at specified distances from the reiease site.' In our alternative procedure, we divided each of the seven rain bins into four bins that depend on rainfall rate, thus increasing the total number of bins to 50 . Sorting of weather sequences on the basis of the amount of rainfall is a potentially irnportant consideration if the CRAC2 wet-deposition model is used, since the scavenging rate depends on rainfall intensity.

We investigated the sensitivity of predicted health impacts to the choice of rain-bin structure using only the CRAC2 wet-deposition model. Four weather sequences were sampled from each of the 29 original bins and two weather sequences from each of the 50 modified bins, so that approximately the same number of trials were selected in each case. For the different values of $\mathrm{RH}$ and $\mathrm{F}$, the alternative procedure changed mean early fatalities by $0-90 \%$, mean early injuries by $3-60 \%$, and mean latent cancer fatalities by less than $15 \%$. However, the changes in early fatalities and injuries may not be significant, because they are similar to variations that result only from selecting different weather ' sequences with the same bin structure. Nonetheless, we feel that the modified bin structure should be incorporated into the code if the CRAC2 wet-deposition model is used. 
The most important results of this study involved the sensitivity of health impacts calculated by the CRAC2 code to changes in the wet-deposition model. In the CRAC2 model, the scavengine rate depends on rainfall rate and atmospheric stability class, whereas the alternative model used a scavenging rate that depends only on storm type, i..e., continuous (frontal) or convective. In single-trial runs involving rain, the alternative model often produced large changes in all health impacts and the effects depended greatly on the characteristics of the weather sequence. The large changes in early fatalities and injuries were also due in part to thresholds in the dose-response modeis in bin-sampling runs, changes of nearly an order of magnitude in predicted mean early fatalities vere observed and changes in mean early injuries were often a factor of $2-3$, but changes in latent cancer fatalities were small. The large changes in eariy fatalities occurred when most of the weather sequences sampled gave a null result, and the effects of the wet-deposition model on mean early fatalities also depinded greatly on whether or not the same weather sequences were sampled in the model comparison. Use of an alternative plume-rise model usually had little effect on health impacts. Moclification of the meteorological bin structure in CRAC2 to include rain bins that depend on rainfall ra?e changed mean heaith impacts by less than a factor of 2 .

\section{REFERENCES}

1. L. T. Ritchie, D. J. Alpert, R. P. Burke, J. D. Johnson, R. M. Ostmeyer, D. C. Aldrich, and R. M. Blond, CRAC2 Model Description, NUREG/CR-2552, SAND82-0342, Sandia National Laboratories (1984).

2. L. R. Ritchie, J. D. Johnson, and R. M. Blond, Calculations of Reactor Accident Consequences, Version 2, CRAC2: Computer Code U'ser's Guide, NUREG/CR-2326, SAND81-1994, Sandia National Laboratories (1983).

3. Reactor Safety Study, Appendix VI: Calculation of Reactor Accident Consequences, WASH-1400 (NUREG 75/014), U.S. Nuclear Regulatory Commission (1975).

4. G. A. Briggs, Plume Rise, TID-25075, U.S. Atomic Energy Commission (1969).

5. G. A. Briggs, "Plume Rise Predictions, " p. 59 in Lectures on Air Pollution and Envirosmental Imnact Analyses American Meteorological Society, Boston, Mass. (1975). 
6. K. P. Makhon'ko, S. G. Malakov, and M. P. Nekhorosheuva, "Washout of Fission Products from the Atmosphere," p. 167 in Radioactive Isotopes in the Atmosphere and Their Use in Meteorology, AEC-TR-6711, U.S. Atomic Energy Commission (1967).

7. A. S. Avramenko and K. P. Makhon'ko, "Atmospheric Washout of Radioactive Contaminant in the Mountains of Central Caucasus," p. 154 in Nuclear Meteorology, National Technical Information Service, Springfield, Virginia (1969).

8. N. Bhandari and Rama, "Study of Atmospheric Washout Processes by Means of Radon Decay Products," J. Geophys. Res. 68, 3823 (1963).

9. B. I. Styra, E. J. Verbra, and K. K. Benninger, "Geochemistry of Atmospheric Radori and Radon Products," Ann Rev. Earth Planet. Sci. 5, 227 (1977).

\section{DISCLAIMER}

This report was prepared as an account of work sponsored by an agency of the United States Government. Neither the United States Government nor any agency thereof, nor any of their employees, makes any warranty, express or implied, or asstumes any legal liability or responsibility for the accuracy, completeness, or usefulness of any information, apparatus, product, or process disclosed, or represents that its use would not infringe privately owned rights. Reference herein to any specific commercial product, process, or service by irade name, trademark, manufacturer, or otherwise does not necessarily constitute or imply its endorsement, recommendation, or favoring by the United States Government or any agency thereof. The views and opinions of authors expressed herein do not necessarily state or reflect those of the United States Government or any agency thereof. 